\title{
RATIONALE OF ACCEPTABLE RISK OF USING TRACTORS WITH OPERATIONAL DAMAGES OF RESPONSIBLE PARTS
} Oleksandr Voinalovych, Leonid Aniskevych,
Myhailo Motrich, Liudmyla Titova

National University of Life and Environmental Sciences of Ukraine, Ukraine voynalov@bigmir.net, 1-anisk@meta.ua,mmi@online.ua, ludmylkatitova@gmail.com

\begin{abstract}
For calculating risk and safety indicators of the tractor it is proposed to use the data of defectoscopic control of the array of responsible tractor parts and to analyze the kinetics of accumulation of the total damage in the array of these parts by analogy with the estimation of the boundary elasticity of the surface layer of metal by multi-cycle fatigue. It is established that the dependence of the kinetics of crack accumulation in parts of systems (units) of the tractor with a high degree of reliability can be described by exponential diagrams within the studied range of service life, which is typical for the pattern of monotonic accumulation in model samples of structural materials of scattered fatigue damage. The description of the kinetics of dispersion of the relative number of defective parts using a 4 degree polynomial allowed to establish a certain maximum corresponding to the interval of 12-13.5 years of the tractor operating life. This maximum corresponds to the maximum intensity of formation of operational cracks for the studied interval of the duration of operation of the tractor and the probability of accumulation in the array of parts of the critical (limit) number of defects. This can serve as a criterion for discontinuing the tractor, performing part flaws to detect cracks and repairing (replacing) defective parts. On the basis of the kinetic diagram of accumulation of operational defects in the array of tractor parts, the method of estimating the residual life of tractors after a certain duration of operation is proposed. This method uses approaches to analyze the kinetics of damage to metallic materials that have undergone mechanical loading, using the Hearst parameter as a criterion, the limiting value of which does not depend on the mechanical loading parameters.
\end{abstract}

Keywords: tractor, flaw control, defectoscopic control, operational cracks, residual resources.

\section{Introduction}

The problem of ensuring reliable operation of mobile agricultural machinery is becoming more urgent, since the speed of its aging far exceeds the pace of technical re-equipment of the agricultural sector of Ukraine [1].Therefore, to predict the failure of tractors, combines and machine-tractor units and, therefore, to prevent possible emergencies in the field and on roads, there is a problem of reliable determination of their residual resource, in particular, how safe their further operation will be after the assigned resource is exhausted [2].

Determining the degree of performance of the machine is important, not less than determining the magnitude of the risk of its operation for the operator or other employees, because the magnitude of the risk should not exceed an acceptable level [3]. At present, acceptable risk levels are generally set for industries and sub-sectors of the economy based on industrial injury statistics, as well as for largescale nuclear facilities, the chemical and metallurgical industries [4].

The operation of mobile agricultural machinery is also considered to be of high risk, but the concept of acceptable (acceptable) risk for mechanical work has no regulatory definition [5]. This does not allow to establish the degree of danger of finding agricultural machinery on the fields, farms and roads without technical means of safety, with exhaustion of the established resource of machinery [6].

Therefore, the introduction of a production risk management system, in which it is necessary to implement the principles of risk prevention, acceptability and minimization, taking into account all potential workplace threats, is relevant for agriculture [7]. This should guarantee by the manager of the enterprise (employer) a certain level of safety for the employees [8].

Establishing time limits for machine operation should not only rely on the strength and economic performance [9], but should also take into account the basic provisions of the concept of risk, which will justify the resource of safe operation [10]. Along with the terms "strength", "resource", "reliability", technicians and operators must evaluate the "safety", "risk" and "security" of employees [11]. And this should apply not only to important and critical production sites, but also to long-lasting machines [12]. 


\section{Materials and methods}

In this paper, to evaluate the risk and safety performance of machines, it is proposed to use the results of studies of defects in materials and structural elements [13], since with increasing the life of the machine, the risk of accidents due to the accumulation of operational defects is continuously increasing [14].

Nowadays, traditional and new methods and means - optical, physical, mechanical, etc. - are used to diagnose the technical condition of machines during routine work [15]. There are virtually no universal methods for detecting several defect parameters, and the most common methods (external examination and magnetic powder flaw detection) allow only large operational cracks to be detected, when the risk of damage is already high [16].

The results of this analysis show that, given the high level of complexity of the control of surface preparation, due to the high complexity of the control of preparation of the controlled surface [17], it is advisable to use most of the methods of defectoscopy developed for examination of local zones with possible damage, rather than general metalwork [18]. For general inspection of metal structures, methods of defectoscopic control, which do not require careful preparation of the surface [19], should be applied, as it was implemented in the framework of this work to study defects in the array of tractor parts [20].

In this work, a portable eddy-current defectoscope (Fig. 1) was used to detect cracks. It allows the detection of cracks longer than $3 \mathrm{~mm}$ andpractically insensitive to surface roughness (capable of detecting defects at the surface roughness $\mathrm{Rz} 60$ and less). The developed device is characterized by the absence of the edge effect, the effect of the sensor removal, allows to detect cracks with a maximum gap between the sensor and the controlled surface up to $3 \mathrm{~mm}$ [21].This made it possible to carry out defectoscopic inspection of a large array of responsible parts of tractors (more than 1200 parts were studied in 50 tractors of different years of manufacture)without preparing controlled surfaces [22].

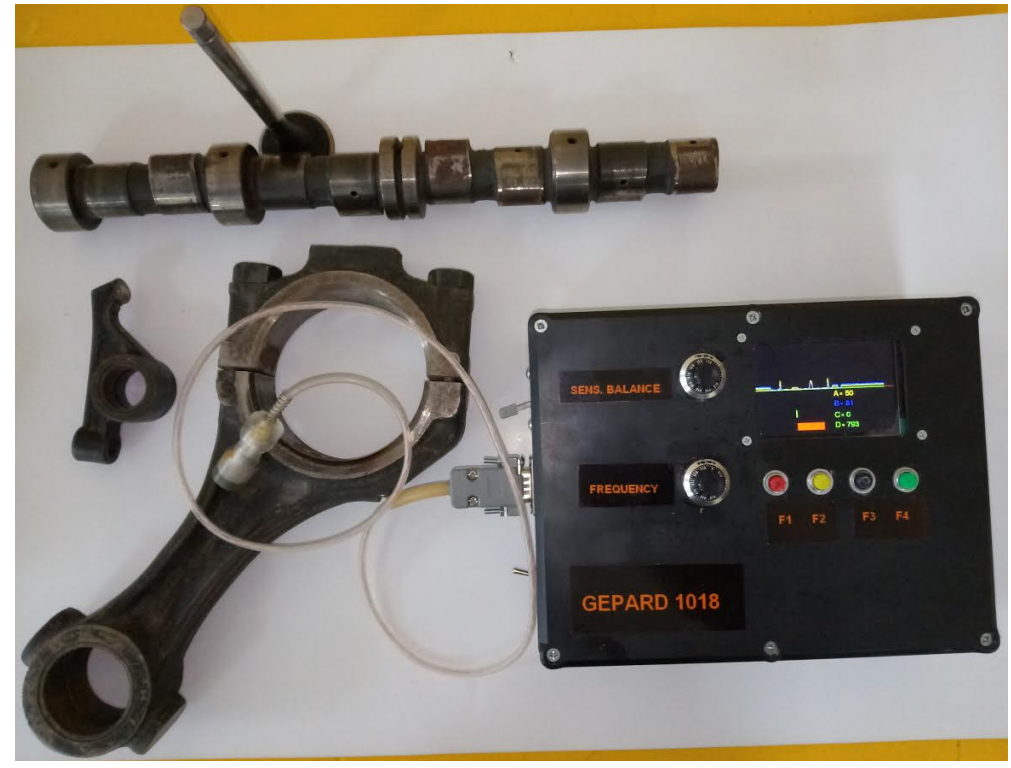

Fig. 1. Portableeddy-current defectoscope

Flaw control was performed during major repairs of tractors with disassembly of separate units.

In order to specify the objects of flaw detection and to narrow the field of detection of cracks, the available parts of individual tractor units were divided into several categories:

1. high voltage parts with high probability of failure;

2. parts, the technical condition of which is conditioned by the aggregate action of force factors with aggressive environmental conditions;

3. parts subject to minor damage;

4. parts, in which damage is detected only visually (small, non-metallic, etc.). 
The proposed methodological approach did not take into account the potential cracking and damage of the third and fourth categories of parts: fasteners, rubber, nonmetallic, etc.

A stepwise sensitivity switch was installed on the defectoscope used to change the minimum size of cracks found in the ranges of 3,5 , and $7 \mathrm{~mm}$ in length, respectively (conventionally named small, medium, and large, depending on the cross-section of the workpiece). As a result of this methodological approach, both kinetic dependences of accumulation of operational defects in components of units with increasing duration of operation of tractors were constructed, as well as kinetic dependences of intensity of the origin of small cracks in the array of the controlled parts.

Flawed inspection of components was carried out for tractors that had been involved in mechanical and transport work for some time, and were subjected to a force load, which led to the emergence of operational cracks.Some of these defects were discovered during the repair of tractors with disassembly of knots. The same was considered with a certain degree of certainty that all the tractors under study at one year of production were in operation for the same period. The 17-year service life of the tractors of the brand under study, which is twice their estimated life, was chosen as the base one.

It is imperative that the defectoscope is inspected for test pieces before defectoscopic examination of parts and structural members. Control samples of cracks of various lengths were obtained on sheet metal alloy samples as a result of the propagation of fatigue cracks from the stress concentrator applied at the edge of the sample.

\section{Results and discussion}

In order to assess the acceptable permissible risk of using mobile agricultural machinery, generalized data were analyzed on the performance of defectoscopic inspection of tractor units [23], which are presented in Table 1.

Table 1

\section{Generalized results of defectoscopic inspection of tractor parts of different years of production}

\begin{tabular}{|c|c|c|c|c|c|c|c|c|c|c|}
\hline \multirow[t]{2}{*}{ No. } & \multirow[t]{2}{*}{ Name of the tractor unit } & \multicolumn{8}{|c|}{$\begin{array}{l}\text { Years of operation of tractors (in brackets is } \\
\text { indicated the number of tractors, which parts have } \\
\text { undergone defective inspection) }\end{array}$} & \multirow[t]{2}{*}{ Total } \\
\hline & & $15(3)$ & $14(8)$ & $13(4)$ & $12(7)$ & $11(7)$ & $10(7)$ & $9(8)$ & $7(7)$ & \\
\hline \multicolumn{11}{|c|}{ Steering system } \\
\hline 1 & Total of cracks detected & 10 & 20 & 10 & 23 & 10 & 13 & 12 & 8 & 114 \\
\hline 2 & All parts were investigated & 22 & 47 & 18 & 43 & 27 & 41 & 48 & 40 & 303 \\
\hline 3 & $\begin{array}{l}\text { Relative number of } \\
\text { defective parts }\end{array}$ & 0.45 & 0.42 & 0.56 & 0.53 & 0.7 & 0.32 & 0.25 & 0.2 & - \\
\hline \multicolumn{11}{|c|}{ Hinged device } \\
\hline 4 & Total of cracks detected & 3 & 18 & 7 & 22 & 9 & 10 & 10 & 9 & 95 \\
\hline 5 & All parts were investigated & 8 & 48 & 15 & 55 & 29 & 34 & 38 & 39 & 278 \\
\hline 6 & $\begin{array}{l}\text { Relative number of } \\
\text { defective parts }\end{array}$ & 0.4 & 0.37 & 0.46 & 0.4 & 0.31 & 0.29 & 0.26 & 0.23 & - \\
\hline \multicolumn{11}{|c|}{ Engine parts } \\
\hline 7 & Total of cracks detected & 4 & 22 & 11 & 17 & 10 & 16 & 9 & 7 & 108 \\
\hline 8 & All parts were investigated & 7 & 45 & 23 & 38 & 26 & 50 & 29 & 28 & 263 \\
\hline 9 & $\begin{array}{l}\text { Relative number of } \\
\text { defective parts }\end{array}$ & 0.56 & 0.48 & 0.47 & 0.44 & 0.39 & 0.32 & 0.31 & 0.25 & - \\
\hline \multicolumn{11}{|c|}{ Rear axle } \\
\hline 10 & Total of cracks detected & 6 & 16 & 7 & 14 & 9 & 8 & 7 & 8 & 80 \\
\hline 11 & All parts were investigated & 13 & 43 & 20 & 41 & 27 & 25 & 23 & 30 & 232 \\
\hline 12 & $\begin{array}{l}\text { Relative number of } \\
\text { defective parts }\end{array}$ & 0.46 & 0.37 & 0.35 & 0.34 & 0.33 & 0.32 & 0.3 & 0.27 & - \\
\hline
\end{tabular}


Table 1 (continued)

\begin{tabular}{|c|c|c|c|c|c|c|c|c|c|c|}
\hline \multirow[t]{2}{*}{$\begin{array}{l}\mathbf{N} \\
\mathbf{o} .\end{array}$} & \multirow[t]{2}{*}{$\begin{array}{c}\text { Name of the tractors } \\
\text { unit }\end{array}$} & \multicolumn{8}{|c|}{$\begin{array}{l}\text { Years of operation of tractors (in brackets is indicated } \\
\text { the number of tractors, which parts have undergone } \\
\text { defective inspection) }\end{array}$} & \multirow[t]{2}{*}{ Total } \\
\hline & & $15(3)$ & $14(8)$ & $13(4)$ & $12(7)$ & $11(7)$ & $10(7)$ & $9(8)$ & $7(7)$ & \\
\hline \multicolumn{11}{|c|}{ Gearbox } \\
\hline 13 & Total of cracks detected & 12 & 11 & 5 & 8 & 9 & 9 & 9 & 7 & 81 \\
\hline 14 & $\begin{array}{l}\text { All parts were } \\
\text { investigated }\end{array}$ & 29 & 35 & 16 & 25 & 31 & 32 & 42 & 39 & 273 \\
\hline 15 & $\begin{array}{l}\text { Relative number of } \\
\text { defective parts }\end{array}$ & 0.41 & 0.31 & 0.31 & 0.32 & 0.29 & 0.28 & 0.21 & 0.18 & - \\
\hline \multicolumn{2}{|c|}{$\begin{array}{l}\text { Total of cracks detected in all } \\
\text { tractors }\end{array}$} & 35 & 87 & 40 & 84 & 47 & 56 & 47 & 39 & 435 \\
\hline \multicolumn{2}{|c|}{$\begin{array}{l}\text { All parts of all tractors were } \\
\text { investigated }\end{array}$} & 79 & 218 & 92 & 202 & 140 & 182 & 180 & 176 & 1269 \\
\hline \multicolumn{2}{|c|}{$\begin{array}{l}\text { Relative number of parts of all } \\
\text { tractors with defects }\end{array}$} & 0.44 & 0.39 & 0.43 & 0.41 & 0.33 & 0.3 & 0.26 & 0.22 & - \\
\hline \multicolumn{2}{|c|}{$\begin{array}{l}\text { Dispersion of the relative } \\
\text { number of defective parts }\end{array}$} & 0.0040 & 0.0040 & 0.0101 & 0.0071 & 0.0017 & 0.000 & 40.0016 & 0.0013 & 0.0040 \\
\hline
\end{tabular}

The kinetics of accumulation of cracks in the parts of systems and assemblies of wheeled tractors of different duration of operation are presented in Fig. 2 and Fig. 3. The coordinates of the graphs are as follows: the ordinate axis is the probability of occurrence of a critical state $P=n_{d} / N$ (the ratio of the number of detected cracks $n_{d}$ in the total set of investigated, meaningful from the point of view of the limit state of operational safety, parts $N$ ); the abscissa axis is the relative durability of $D=t_{e k s} / t_{b a z}$ (the ratio of the duration of operation of the tractors $t_{e k s}$ to the base duration $t_{b a z}$, which is 17 years in the calculations). The experimental data for the individual tractor operating ranges are described by the trend lines of exponential type. In Fig. 2 and Fig. 3, their equations and the reliability of the approximation of $R^{2}$ are written. The obtained results correspond to the normal distribution.

The exponential form for graph representation in Fig. 2 and Fig. 3 are selected for the maximum confidence of the approximation of $R^{2}$ by the trend line. The reliability of linear dependence approximation is lower, as evidenced by the data in Table 2 .

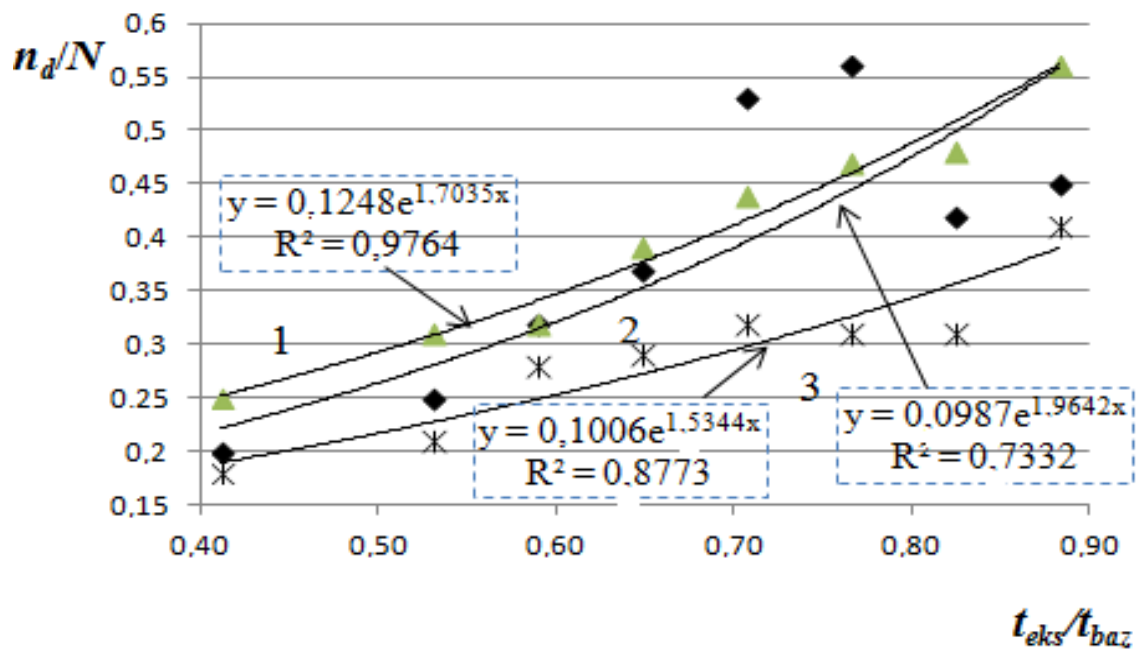

Fig. 2. Kinetics of crack accumulation in engine parts (curve 1), steering system (curve 2) and gearboxes (curve 3 ) of wheeled tractors of different duration of operation

The exponentiality of the trend line in Fig. 2 and Fig. 3 reflect a certain increase in the intensity of defect accumulation in the array of tractor parts with an increase in the service life, which was found in the presence of the maximum in Fig. 3. This made it possible to propose a criterion for the risk of continuation of the tractor without defectoscopic control. 


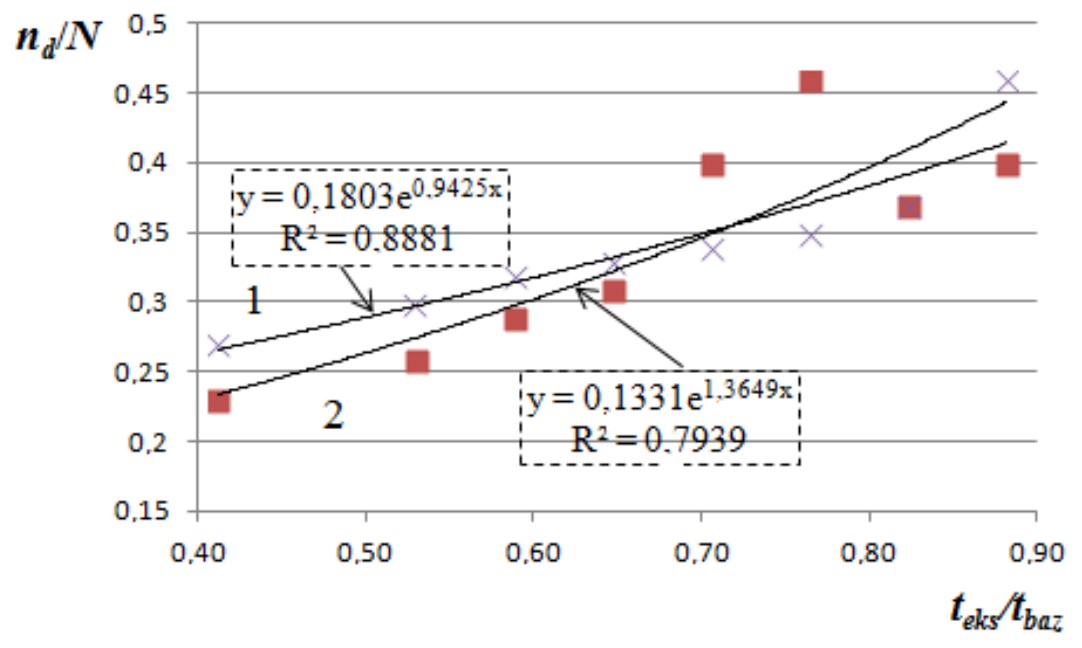

Fig. 3. Kinetics of accumulation of cracks in parts of the rear axle (curve 1) and the hinged device (curve 2) of wheel tractors of different duration of operation

The dispersion kinetics $\sigma$ of the obtained values of the relative number of defective parts for the considered knots and tractor systems was analyzed (Fig. 4). The graphs in Fig. 4 are based on statistical processing of a data set of 40 elements, and each point on the graph corresponds to a variance of 5 values obtained as a result of averaging the results of defectoscopic control of at least 232 tractor parts. The results of the calculation of the dispersionwere described by a polynomial of 4 degrees with a clear maximum corresponding to the duration of operation in the range of $0.7-0.8$ relative duration of operation, which is $12-13.5$ years. The presence of this maximum can be explained by the maximum intensity of formation of operational cracks in the given duration of operation of the tractor, which indicates the danger of its further use without proper control of the technical condition with the involvement of means of flaw detection to detect large (critical size) cracks.

Table 2

Comparison of the reliability of the approximation $R^{2}$ for different tractor units

\begin{tabular}{|c|c|c|}
\hline \multirow{2}{*}{$\begin{array}{c}\text { Name of the } \\
\text { tractors unit }\end{array}$} & \multicolumn{2}{|c|}{ Reliability of the approximation $\boldsymbol{R}^{\mathbf{2}}$} \\
\cline { 2 - 3 } Steering system & Exponential dependence & Linear dependence \\
\hline Hinged device & 0.7332 & 0.6537 \\
\hline Engine parts & 0.7939 & 0.7399 \\
\hline Rear axle & 0.9764 & 0.9707 \\
\hline Gearbox & 0.8881 & 0.8311 \\
\hline
\end{tabular}

The same critical duration of the tractor operation (12-13.5 years) can serve as a criterion for termination of the tractor operation, flaw detection of parts to detect cracks and repair (replacement) of defective parts. The highest correlation coefficients characterize the kinetics of accumulation of cracks in: the steering system and attachment; engine and rear axle with tractor gearbox (Table 3).

Table 3

\section{Correlation coefficients of kinetics of accumulation of operational defects for different tractor systems (units)}

\begin{tabular}{|l|c|c|c|c|}
\hline \multirow{2}{*}{$\begin{array}{c}\text { Name of tractor } \\
\text { system (units) }\end{array}$} & Hinged device & Engine & Rear axle & Gearbox \\
\cline { 2 - 5 } & \multicolumn{4}{|c|}{ Correlation coefficients } \\
\hline Steering system & 0.977094 & 0.823954 & 0.601399 & 0.766263 \\
\hline Hinged device & - & 0.877112 & 0.682509 & 0.789921 \\
\hline Engine & - & - & 0.925974 & 0.936178 \\
\hline Rear axle & - & - & - & 0.94546 \\
\hline
\end{tabular}

The diagram of Fig. 5 shows that the dispersion of accumulation of operational defects is significantly different for different systems (units) of the tractor. The description of the results of 
studies of the kinetics of the accumulation of damage by exponential dependences is preferred over linear dependencies not only in view of the approximation reliability. The lowest is for the rear axle and gearbox consisting of the same parts, and the highest for the steering system. This imposes high demands on the flaw detection of parts of this system, the destruction of which can lead to accidents with a high risk of injury to employees.

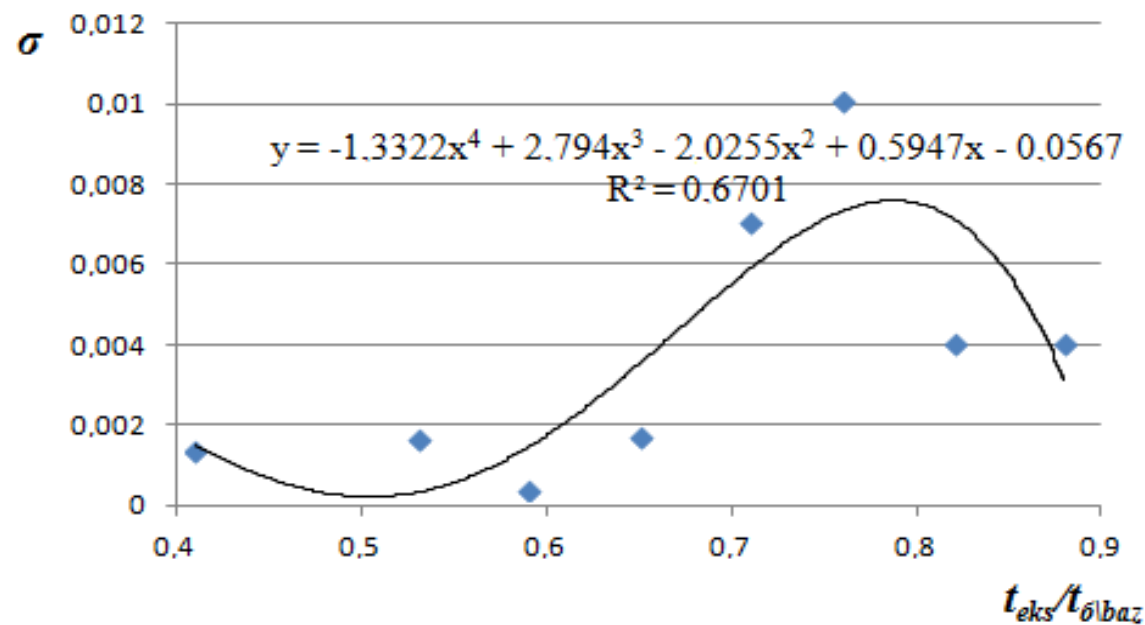

Fig. 4. Kinetics of dispersion $\sigma$ of the obtained values of the relative number of defective parts for the considered components and tractor systems

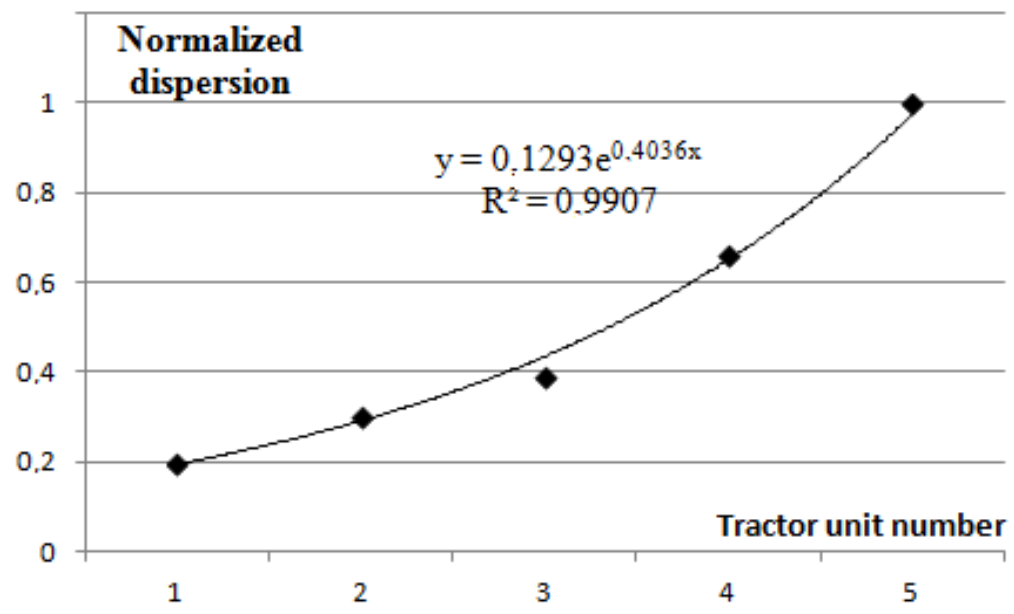

Fig. 5. Diagram of dispersion of accumulation of operational defects for different tractor systems (units): 1 - rear axle; 2 - transmission; 3 - hinged device; 4 - engine; 5 - steering system

Presented in Fig. 2 and Fig. 3, the dependences of the kinetics of accumulation of cracks in the parts of tractor systems (units) are exponential within the investigated operating life span. It should be noted that the exponential dependence is characteristic of the laws of monotonic accumulation in samples of structural materials of scattered fatigue damage represented by the Hearst parameter $(H)$.

To predict the remaining life of a machine with exhausted service life, you need to solve two problems:

- to evaluate the current technical status on the basis of data collected during examination (diagnosis, defect) of materials;

- to determine the residual resource on the basis of forecasting the development of this state to the limit.

As a rule, the current technical condition of the machine is evaluated according to various parameters, and the residual resource is predicted according to the determining parameter of the technical condition of the machine.

The proposed in this work methodology for predicting the residual life of a metal structure is based on the principles implemented in the method of analysis of the damage kinetics of metallic 
materials that have undergone mechanical loading in accordance with changes of the Hearst parameter $H$. Diagrams of accumulation of operational defects in the arrays of parts of individual systems (units) of tractors were analyzed analogously to the graphs of kinetics of statistical parameters of deformation hysteresis of the surface layer of metal structures.

The same as the criterion of the degree of accumulation of operational defects, which can cause accidents in mechanized and transport works with the participation of tractors, by analogy in this work, the probability of accumulation in the array of parts of the critical (limit) number of defects was taken.

Fig. 6 presents a diagram to illustrate the proposed in this paper method for estimation of the residual resource $\left(D_{\text {lim }}-D_{\text {fact }}\right)$ of tractors after a certain duration $D_{\text {fact }}$ of operation based on a kinetic diagram of the accumulation of operational defects in the array of wheeled tractor parts, obtained by averaging the defect control data. The coordinates of the diagram correspond to the coordinates of the diagrams in Fig. 2 and Fig. 3.

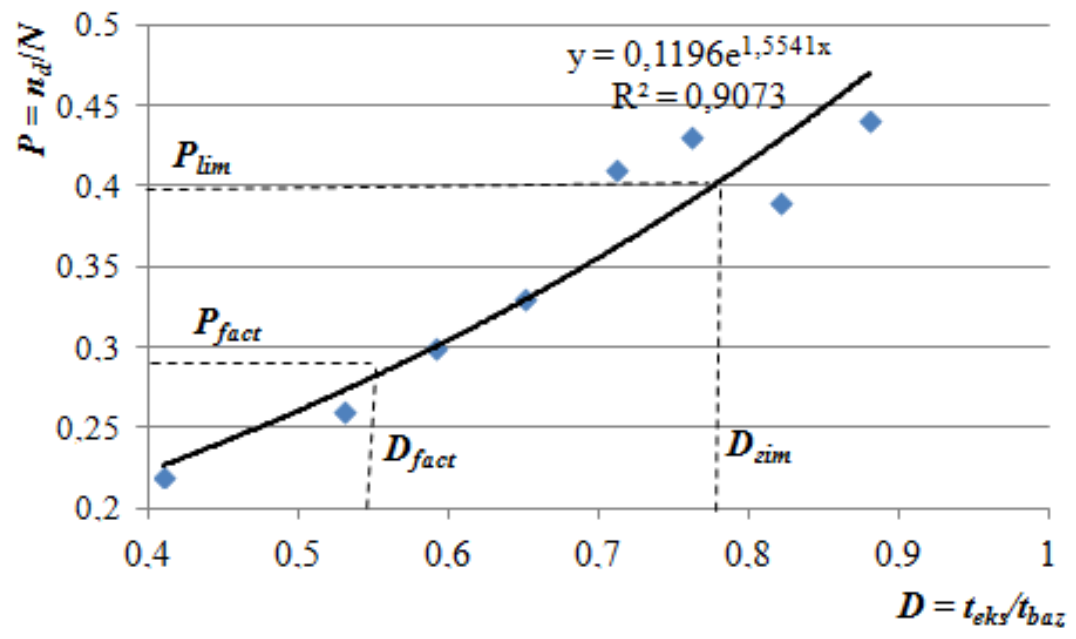

Fig. 6. Scheme of the method of estimating the residual life of tractors after their long operation

Fig. 4 shows the relative duration of operation, when the intensity of cracks is maximum, and therefore, if this value is exceeded, the probability of sudden destruction of tractor units and the creation of accidents in mechanized or transport operations is increased. For the studied wheeled tractor units, this value $\left(D_{\text {lim }}\right)$ is approximately the same and is in the range of 0.7-0.8 relative operating life that is about 12-13.5 years. The actual duration $\left(D_{\text {fact }}\right)$ of tractor operation can be estimated by detecting a certain number of defects (cracks) in an array of parts, calculating their relative number in the total set of the investigated parts, and drawing the horizontal line to the curve of intensity of the accumulation of operational cracks, as shown in Fig. 6.

The procedure for estimating the residual life of the tractors or their individual units (systems) after prolonged operation is as follows.

1. With the help of a portable flaw detector, carry out flaw detection of the array of responsible tractor parts.

2. Determine which part $\left(P_{\text {fact }}=n_{\partial} / N\right)$ of the array of parts has operational defects relative to the total number of parts $N$ that are subject to flaw control.

3. According to the year of tractor production, set its relative duration of operation $\left(D_{f a c t}=t_{e x p} / t_{b a z}\right)$ relative to the base term ( $t_{b a z}=17$ years).

4. Through the point with coordinates $\left(P_{\text {fact }}, D_{\text {fact }}\right)$ in Fig. 6 conduct an exponential curve with parameters corresponding to the trend line parameters of the exponential accumulation defect accumulation curve obtained by averaging the data. With some approximation, we can take the parameters of the exponent $a=0.119 ; b=1.5541$.

5. For the limit accumulation of operational defects $P_{\text {lim }}=0.4$, we draw a horizontal line to intersect with the exponential curve. The abscissa of the intersection point will correspond to the maximum duration of operation of the tractor $D_{l i m}$, and the difference $\left(D_{l i m}-D_{\text {fact }}\right)$ to its residual resource. 
To estimate the residual life of individual units (systems) of a tractor, it is necessary to use the parameters of the corresponding exponential curves shown in Fig. 2 and Fig. 3. However, it should be noted that the general analysis of the kinetics of the obtained data (Fig. 2 and Fig. 3) does not allow to reliably predict the parameters of the kinetics of crack accumulation in the parts (units) of the tractors beyond the studied service life (17 years).

In other areas we may also find some analogues to the proposed methodology for estimating the residual life of tractors after prolonged use. Thus, a sufficient statistical base of experimental data on occurrence of defects was collected and analyzed to determine the technical condition of induction motors. The performed researches made it possible to construct the criterion of maximum accumulation of defects in induction motors, which made it possible to predict the technical condition of the induction motor in the aggregate of accumulated defects and to stop it in a timely manner, avoiding significant damage to the machine components and accidents.

\section{Conclusions}

1. The analysis of the generalized data of defectoscopic inspection of tractors made it possible to justify the terms of use of mobile agricultural machinery without exceeding the acceptable permissible risk.

2. It is shown that the results of the calculation of the dispersion of the obtained values of the relative number of defective parts for the considered systems (units) of tractors can be described by a polynomial with a clear maximum corresponding to the duration of operation in the range of $0.7-0.8$ relative duration of operation, which is $12-13.5$ years. The presence of this maximum corresponds to the maximum intensity of formation of operational cracks, which indicates the danger of further use of the machine without proper inspection of the technical condition with the use of flaw detection to detect large (critical) cracks.

3. The methodology of estimation of the residual life of tractors or their separate units (systems) after long operation on the basis of the data of defectoscopic control is developed. This methodology is based on the approaches of the method of analysis of the kinetics of damage of metallic materials that have undergone mechanical loading, according to changes in the Hearst parameter, which limit value, expressed by a fixed value, does not depend on the parameters of mechanical loading.

\section{Acknowledgements}

This work was supported by a grant of the Ministry of Science and Education of Ukraine, contract _110/495/01.01.2016, Project code: UA 1649501 01, NULES Project title - "Experimental researches of parameters and modes of functioning of system of maintenance of agricultural machinery", phase 6: Experimental researches of parameters and modes of functioning of system of operational safety for agricultural aggregates.

\section{References}

[1] Bulgakov V., Adamchuk V., Ivanovs S., Kaletnik H. Experimental investigation of technical and operational indices of asymmetric swath reaper machine-and-tractor aggregate. Proceedings of 18th International Scientific Conference "Engineering for rural development". Jelgava, Latvia, May 22-25, 2019, Latvia University of Agriculture. Faculty of Engineering, vol. 18, pp. 256-263.

[2] Najafi P., Asoodar M. A., Marzban A., HormoziM. A. Reliability analysis of agricultural machinery: A case study of sugarcane chopper harvester.AgricEngInt: CIGR Journal. March, 2015,vol. 17, no. 1, pp. 158-165.

[3] Gurcanli E., Bilir S., Sevim M. Activity Based Risk Assessment and Safety Cost Estimation for Residential Building Construction Projects. Safety Science, 2015, vol. 80, pp. 1-12.

[4] Khamidullina E.A., Timofeeva S.S., Smirnov G.I. Accidents in Coal Mining from Perspective of Risk Theory. IOP Conference Series: Materials Science and Engineering, 2017,vol. 262, 012210.

[5] AvenT. Risk assessment and risk management: Review of recent advances on their foundation. European Journal of Operational Research, 2016,vol. 253, issue 1, pp. 1-13.

[6] Tyutrin S. Improving reliability of parts of mounted mower according to monitoring results by fatigue gauges from tin foil.Proceedings of 18th International Scientific Conference "Engineering 
for rural development". Jelgava, Latvia, May 22-25, 2019, Latvia University of Agriculture. Faculty of Engineering, vol. 18, pp. 22-27.

[7] Bulgakov V., Pascuzzi S., Nadykto V., Ivanovs S. A mathematical model of the plane-parallel movement of an asymmetric machine and tractor aggregate. Journal of Agricultural Engineering, 2018, vol. 49, no 1, pp. 258-271.

[8] Voinalovych O., Hnatiuk O., Rogovskii I., Pokutnii O. Probability of traumatic situations in mechanized processes in agriculture using mathematical apparatus of Markov chain method. Proceedings of 18th International Scientific Conference "Engineering for rural development". Jelgava, Latvia, May 22-25, 2019, Latvia University of Agriculture. Faculty of Engineering, vol. 18 , pp. 563-269.

[9] Rogovskii I., Titova L., Novitskii A., Rebenko V. Research of vibroacoustic diagnostics of fuel system of engines of combine harvesters. Proceedings of 18th International Scientific Conference "Engineering for rural development". Jelgava, Latvia, May 22-25, 2019, Latvia University of Agriculture. Faculty of Engineering, vol. 18, pp. 291-298.

[10] Duan F., Živanovi'c R., Al-Sarawi S., Mba, D. Induction motor parameter estimation using sparse grid optimization algorithm. IEEE Trans. Ind. Inf, 2016, vol. 12, pp. 1453-1461.

[11] Shih-Heng T., Ming-Hsiang S., Wen-Pei S. Development of digital image correlation method to analyse crack variations of masonry wall. Sadhana, 2008,vol.6,pp. 767-779.

[12] Gyansah L.,Ansah A.K. Fatigue Crack Initiation Analysis in 1060 Steel.Res. J.ofAppl. Sc. Eng.and Tech,2010,vol.4,issue 2,pp. 319-325.

[13] Bulgakov V., Nadykto V., Ivanovs S., Nowak J. Research of variants to improve steerability of movement of trailed asymmetric harvesting aggregate. Proceedings of 18th International Scientific Conference "Engineering for rural development". Jelgava, Latvia, May 22-25, 2019, Latvia University of Agriculture. Faculty of Engineering, vol. 18, pp. 136-143. Scopus.

[14] NykyforchynH., Lunarska E., Tsyrulnyk O., et al. Environmentally assisted "in-bulk" steel degradation of long term service gas trunkline. Engineering Failure Analysis, 2010,vol. 17,pp. 624-632.

[15] Trokhaniak V.I., Rutylo M.I., Rogovskii I.L., Titova L.L., Luzan O.R., Bannyi O.O. Experimental studies and numerical simulation of speed modes of air environment in a poultry house. INMATEH. Agricultural Engineering. Bucharest, 2019, vol. 59, no 3, pp. 9-18. Scopus.

[16] Corinne Berzin, José R. León. Estimating the Hurst parameter. Statistical Inference for Stochastic Processes. Springer Verlag, 2007,vol.10 (1), pp. 49-73.

[17] Ruzhylo M.J., Skorokhod T.A. On empirical distributions in spaces of growing dimensions. Discrete distributions. Random operators and stochastic equations, The Netherlands, 2005, vol. 3 , pp. 210-219.

[18] Kypris O., Nlebedim I.C., Jiles D. Measuring stress variation with depth using Barkhausen signal. J. Magn. Magn. Mater, 2016,vol. 407, pp. 377-395.

[19] Erokhin M., Pastukhov A., Kazantsev S. Operability assessment of drive shafts of John Deere tractors in operational parameters. Proceedings of 18th International Scientific Conference "Engineering for rural development". Jelgava, Latvia, May 22-25, 2019, Latvia University of Agriculture. Faculty of Engineering, vol. 18, pp. 28-33.

[20] Xi L., Songlin Z. Changes in mechanical properties of vehicle components after strengthening under low-amplitude loads below the fatigue limit. Fatigue and Fracture of Engineering Materials and Structures, 2019,vol. 32,no. 10, pp. 847-855.

[21] Ruzhylo, M.J., Skorokhod T.A. On empirical distributions in spaces of growing dimensions. Continuous distributions. Random operators and stochastic equations, The Netherlands, 2005, vol. 4, pp. 184-193.

[22] Rejovitzky E., Altus E. On single damage variable models for fatigue. International Journal of Damage Mechanics, 2013,vol. 22,no. 2, pp. 268-284.

[23] Pisarenko G., Voinalovych O., Rogovskii I., Motrich M. Probability of boundary exhaustion of resources as factor of operational safety for agricultural aggregates. Proceedings of 18th International Scientific Conference "Engineering for rural development". Jelgava, Latvia, May 22-25, 2019, Latvia University of Agriculture. Faculty of Engineering, vol. 18, pp. 291-298. 